\title{
Fermentation of Persea americana Seed Flour Using Lactobacillus plantarum and Investigate Its' Effect on Nutritional Quality
}

\author{
P.D.S.R. Kumari and R. Amarakoon
}

\section{ABSTRACT}

This study aims to investigate the fermentation of Avocado seed flour using Lactobacillus plantarum. Proximate composition and most important mineral contents of Avocado seed flour after fermenting for 24, 48 and $72 \mathrm{~h}$ were compared with dry unfermented Avocado seed flour. Avocado seed flour fermented for $72 \mathrm{~h}$ had significant increase $(p<0.05)$ of crude protein content from $6.42 \pm 0.08 \%$ to $9.26 \pm 0.28 \%$. Mineral contents were determined by Atomic Absorption Spectrophotometer. $\mathrm{Ca}, \mathrm{Mg}, \mathrm{Fe}$ contents of dry unfermented Avocado seed flour were $208.89 \pm 0.3 \mu \mathrm{g} / \mathrm{g}, 99.05 \pm 0.01 \mu \mathrm{g} / \mathrm{g}$, $9.04 \pm 0.01 \mu \mathrm{g} / \mathrm{g}$ and fermented Avocado seed flour $(72 \mathrm{~h})$ were $227.06 \pm 0.050$ $\mu \mathrm{g} / \mathrm{g}, 189.22 \pm 0.33 \mu \mathrm{g} / \mathrm{g}$, and $18.11 \pm 0.006 \mu \mathrm{g} / \mathrm{g}$ respectively. There is a significant increase $(\mathrm{p}<0.05)$ of $\mathrm{Ca}, \mathrm{Mg}$ and Fe content of fermented (72 h) Avocado seed flour. Fermentation of Avocado seed flour for $72 \mathrm{~h}$ enhance the nutritional quality.

Keywords: Avocado seeds, Lactobacillus plantarum, Mineral content, Proximate composition.
Submitted : August 24, 2021

Published : September 14, 2021

ISSN: $2684-1827$

DOI: 10.24018 /ejfood.2021.3.5.363

\section{P.D.S.R. Kumari*}

Department of Microbiology, University Kelaniya, Sri Lanka.

(e-mail: surekadilushi@gmail.com) R. Amarakoon

Department of Microbiology, University Kelaniya, Sri Lanka.

(e-mail: ranjaniam@ $\left.{ }^{@} \mathrm{kn} . \mathrm{ac} . \mathrm{lk}\right)$

\section{INTRODUCTION}

The Persea americana, commonly known as avocado is a local fruit that has a wide distribution around the tropical region of the globe. Avocado is a nutrient dense fruit. The smooth flavour of avocado has attracted as an oleaginous fruit crop around the world. Furthermore, ease of cultivation and management contribute towards cultivating this crop as a raw dietary supplement and for pharmaceutical preparations [1].

Avocado seeds, which represent $16 \%$ of total fruit mass on a wet basis are considered as a waste product in food industries. Therefore, it has become an underutilized product. Avocado seeds are enriched with several phytochemicals which can be nutritionally and medically important. [2] The Avocado seeds has $70 \%$ of the antioxidants found in the whole avocado, and it is full of antioxidants that can lower cholesterol and fighting many diseases [2]. Studies have shown that Avocado seeds have more soluble fibre than oatmeal and just above any other food. Vital compounds in Avocado seeds boost the immune system and is a deterrent towards debilitating diseases. The Avocado seeds seem to have a good anti-inflammatory ability which can help in arthritis and other diseases [2]. The Avocado seeds oil can increase the collagen in the skin thus helping to keep skin looking young and wrinkle-free. Further, it makes the hair shiny and helps to get rid of dry and dead skin [3].

Currently, the exploitation of non-edible parts of fruits including seeds has emerged as a trending approach to mitigate the increase of wastes in the food industry [3]. Bioactive compounds within the underutilized parts of fruits can often be inactive. Bioactive substances produced during fermentation can have enhanced functionalities, thereby the quality of foods can be improved. Hence, microbial fermentation and fermentation using enzymes from plants or microorganisms are used to upgrade the quality. These production approaches have their advantages and disadvantages [4]. Therefore, the microbiological method of fermentation of the raw material can transform it into a processed product with added value. Lactic Acid Bacteria as a starter culture is preferred as against other starter bacterial cultures due to the high safety handling. [4]. These bacteria are very common are widely used as a simpler and costeffective method in food and beverage production to improve nutritional quality, functional properties as well as to improve sensory characteristics [5].

There were no studies found in fermenting of Avocado seed flour by using food grade microorganism in Sri Lanka but done elsewhere. Therefore, this research was designed to investigate the fermentation of Avocado seed flour by using Lactobacillus plantarum. Further, it is aimed to develop an instant beverage out of fermented Avocado seed flour for consumption.

\section{METHOD}

\section{A. Sample Collection and Storage}

Ripen Avocado fruit of a common local variety in Sri Lanka were taken for the experiment. The seeds of Avocado fruits were collected by removing the fleshy part of the fruit. Seeds were subjected to steam blanching after slicing into 2 
$\mathrm{mm}$ thick slices. The blanched slices were dried in an oven to obtain a constant weight which maintained at $50{ }^{\circ} \mathrm{C}$. Dried samples were sealed and hygienically packed in an airtight container for further analysis at the laboratory of microbiology.

\section{B. Maintenance of L. plantarum Cultures}

L. plantarum cultures required for the fermentation process were obtained from the culture collection of the Department of Microbiology, Faculty of Science, University of Kelaniya, Sri Lanka. The L. plantarum cultures were stored under $-80{ }^{\circ} \mathrm{C}$ refrigerator maintained in sterile MRS broth with glycerol $(20 \%)$ where the working cultures of $L$. plantarum were maintained on sterile MRSA plates maintained at $37^{\circ} \mathrm{C}$ and routinely sub-cultured every four-week time.

\section{Preparation of L. plantarum starter Culture}

L. plantarum starter cultures were prepared as described in [6] with some modifications. The stock cultures that were grown in MRS broth $(10.0 \mathrm{~mL})$ at $37{ }^{\circ} \mathrm{C}$ for $48 \mathrm{~h}$ were inoculated into sterile MRS broth $(10 \% \mathrm{w} / \mathrm{v}, 50.0 \mathrm{~mL})$ with Avocado Seed Flour (2.5 g), refined sugar (1.5 g), skim milk $(1.0 \mathrm{~g})$ and incubated at $37^{\circ} \mathrm{C}$ for $24 \mathrm{~h}$.

\section{Preparation of Dry Unfermented and Fermented Avocado Seed Flour}

Four different samples were prepared by adding dried Avocado seed chips (50.0 g) into conical flasks with sterile distilled water (SDW, $500.0 \mathrm{~mL}$ ). Thereafter each flask was sterilized in an autoclave at $121^{\circ} \mathrm{C}$ for 5 minutes, the prepared starter cultures of $L$. plantarum were transferred into three flasks to perform the fermentation process for different time durations such as $24 \mathrm{~h}, 48 \mathrm{~h}$, and $72 \mathrm{~h}$ at $37^{\circ} \mathrm{C}$. After the fermentation, Avocado chips were washed with sterile distilled water and soaked in salt solution $(10 \%, 500 \mathrm{~mL})$ for 15 minutes. Thereafter wash it thrice with sterile distilled water to remove salt residues. Each fermented Avocado seed sample was oven-dried at $55^{\circ} \mathrm{C}$ for 2-3 days. The dried chips were ground by using a blender and sieved with $8 \mathrm{~mm}$ mesh size.

\section{E. Analysis of the Proximate Composition of Fermented and Unfermented Avocado Seed Flour}

The method of analysis of the proximate composition of the Avocado seed flour is as described by [7], with slight modifications. The Proximate composition were analysed for both unfermented and fermented Avocado seed flour ( $24 \mathrm{~h}$, $48 \mathrm{~h}$, and $72 \mathrm{~h}$ ) for the contents of moisture, crude protein, crude fibre, crude fat, ash, and total carbohydrate in triplicates.

\section{1) Determination of moisture content}

The method described in [7], with slight modifications was followed for the determination of moisture content of each avocado flour sample. Sample (3.00 g) was weighed into preweighed Petri dishes and dried in the oven (Philip Harris, UK) at $105 \pm 1{ }^{\circ} \mathrm{C} \pm 1$ for $2-3 \mathrm{~h}$ until a constant weight was maintained. Final dried samples were cooled and weighed.

\section{2) Determination of crude protein content}

The micro-Kjeldahl method of nitrogen analysis described in [7], with slight modifications was followed to determine the crude protein content of each dried avocado flour sample.
Sample (3.00 g) was added into a digesting tube that contained $25.00 \mathrm{~mL}$ of conc. $\mathrm{H}_{2} \mathrm{SO}_{4}$ and one catalyst tablet was heated at low temperatures for digestion. The digested Avocado seed flour samples were diluted with distilled water $(100.0 \mathrm{~mL})$ and $\mathrm{NaOH}(40 \%, 10.0 \mathrm{~mL})$. In the presence of the Kjeldahl indicator, liberated $\mathrm{NH}_{3}$ collected into a boric acid solution $(4 \%, 10.0 \mathrm{ml})$, was titrated with $\mathrm{HCl}(0.1 \mathrm{M})$. A blank was prepared without a sample.

\section{3) Determination of crude fibre content}

Crude fibre content was determined according to the method described in [7], with slight modifications. Defatted Avocado seed flour samples (3.00 g) were measured and added into a conical flask which contained $\mathrm{H}_{2} \mathrm{SO}_{4}$ acid $(5 \%$, $200.0 \mathrm{ml}$ ) and Sodium hydroxide (5\%, $200.0 \mathrm{ml}$ ), respectively and the content was bought to the boiling point and kept boiling for 40 minutes while stirring with a glass rod keeping the volume constant by adding hot water time to time. The residues collected by filtering the content through the Buchner funnel into a filter paper, were dried at $105 \pm 1{ }^{\circ} \mathrm{C}$ in the oven (Philip Harris, UK) and, in the Muffle furnace (Wise Therma, South Korea) dried Avocado seed flour samples were ashed at $550 \pm 5^{\circ} \mathrm{C}$.

\section{4) Determination of ash content}

Ash content was determined according to the method described in [7], with slight modifications. Sample (3.00 g) was weighed into a pre-weighed porcelain crucible and incinerated in a muffle furnace (Wise Therm, South Korea) at $550{ }^{\circ} \mathrm{C}$ for $6 \mathrm{~h}$ until a light grey ash was observed, and a constant weight obtained. The Avocado seed flour sample was cooled and weighed to obtain ash content.

\section{5) Determination of crude fat content}

The method described in [7], with some modifications was followed for the determination of the crude fat content of each Avocado seed flour sample. By using a Mojonnier flask, that was used to extract the fat of each dried Avocado seed flour sample with Hydrochloric acid (6N), crude fat content was determined.

\section{6) Determination of total carbohydrate content}

From the determined proximate contents, the carbohydrate content of each dry unfermented and fermented avocado seed flour sample was calculated by the following formula:

$$
\begin{gathered}
\text { Carbohydrate }(\%)=100-(\text { moisture } \%+\text { ash } \%+\text { crude } \\
\text { protein } \%+\text { crude fat } \%+\text { crude fibre } \%)
\end{gathered}
$$

\section{F. Analysis of Minerals of Unfermented and Fermented Avocado Seed Flour}

The method of wet acid digestion described in [8], was employed to the determination of the concentration of sodium, potassium, calcium, magnesium, and iron of each Avocado seed flour sample by using an Atomic Absorption Spectrometer (GBC 2000, SavantAA).

\section{G. Statistical Analysis}

Data obtained in triplicates were carried out by one-way analysis of variance (ANOVA) technique. The Tukey's multiple comparison test used to identify the means that differ significantly at $\mathrm{p}<0.05$. Results were expressed as mean \pm 
standard deviation, standard deviation of triplicate for proximate composition and minerals analysis which is important.

\section{RESULtS}

The results obtained for proximate composition analysis by

The graph of Nutrient content (\%) vs Fermentation time(h)

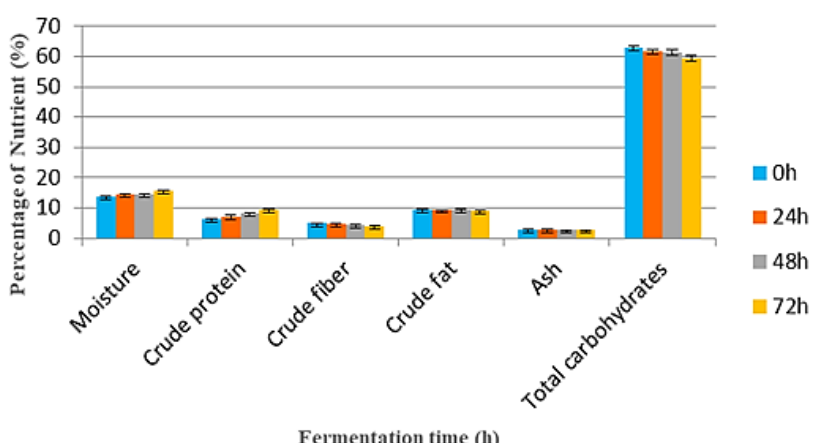

Fig. 1. Effect of fermentation of L. plantarum on the nutrient content of Avocado Seed flour $(n=3)$. Bars represent the mean \pm standard deviation. Same letters mean no statistical difference between treatments at Tukey Pairwise Comparisons, $\mathrm{p}<0.05$. nutritional assay of unfermented and fermented avocado seed flour samples (Table I) is shown in bar charts (Fig. 1). The composition of the most important minerals of dry unfermented and fermented Avocado seed flour samples (Table II) by the Atomic Absorption Spectroscopic analysis is shown in bar charts (Fig. 2). Those results were compared by one way ANOVA technique and Tukey's multiple comparison test.

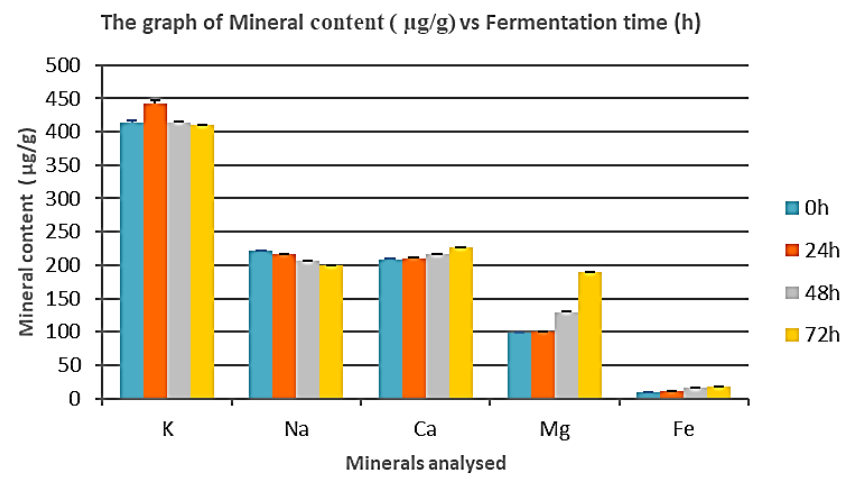

Fig. 2. Effect of fermentation of L. plantarum on the mineral content of Avocado Seed flour $(n=3)$. Bars represent the mean \pm standard deviation. Same letters mean no statistical difference between treatments at Tukey Pairwise Comparisons, $\mathrm{p}<0.05$.

TABLE I: RESUltS OF PROXIMATE COMPOSITION OF UNFERMENTED AND FERMENTED AVOCADO SEED FLOUR

\begin{tabular}{ccccccc}
\hline \multirow{2}{*}{ Fermentation time $(\mathrm{h})$} & \multicolumn{4}{c}{ Nutrient content (\%) } \\
\cline { 2 - 6 } & Moisture content* & $\begin{array}{c}\text { Crude protein } \\
\text { content* }\end{array}$ & $\begin{array}{c}\text { Crude fiber } \\
\text { content* }^{*}\end{array}$ & $\begin{array}{c}\text { Crude fat } \\
\text { content* }\end{array}$ & Ash content* & Total carbohydrates* \\
\hline 0 & $13.63^{\mathrm{A}} \pm 0.40$ & $6.42^{\mathrm{D}} \pm 0.08$ & $4.90^{\mathrm{A}} \pm 0.13$ & $9.30^{\mathrm{A}} \pm 0.08$ & $2.82^{\mathrm{A}} \pm 0.08$ \\
24 & $14.29^{\mathrm{A}} \pm 0.34$ & $7.22^{\mathrm{C}} \pm 0.25$ & $4.85^{\mathrm{A}} \pm 0.09$ & $9.29^{\mathrm{A}} \pm 0.04$ & $2.63^{\mathrm{A}} \pm 0.14$ & $62.92^{\mathrm{A}} \pm 0.61$ \\
48 & $14.41^{\mathrm{A}} \pm 0.31$ & $8.20^{\mathrm{B}} \pm 0.26$ & $4.14^{\mathrm{B}} \pm 0.34$ & $9.26^{\mathrm{A}} \pm 0.27$ & $2.64^{\mathrm{A}} \pm 0.09$ \\
72 & $15.57^{\mathrm{A}} \pm 0.30$ & $9.26^{\mathrm{A}} \pm 0.28$ & $4.05^{\mathrm{B}} \pm 0.16$ & $8.97^{\mathrm{A}} \pm 0.06$ & $2.58^{\mathrm{A}} \pm 0.05$ \\
\hline
\end{tabular}

$*$ The values are mean \pm standard deviation of the replicates.

The values with common superscript letters in each column are not significantly different $(\mathrm{p}<0.05)$.

TABLE II: RESUlTS OF MOST IMPORTANT MINERALS CONTENT OF UNFERMENTED AND FERMENTED AVOCADO SEED FLOUR

\begin{tabular}{|c|c|c|c|c|}
\hline \multirow[b]{2}{*}{ Mineral } & \multicolumn{4}{|c|}{ Mineral content $(\mu \mathrm{g} / \mathrm{g})$} \\
\hline & Unfermented flour & $\begin{array}{c}24 \mathrm{~h} \\
\text { fermented flour }\end{array}$ & $\begin{array}{c}48 \mathrm{~h} \\
\text { fermented flour }\end{array}$ & $\begin{array}{c}72 \mathrm{~h} \\
\text { fermented flour }\end{array}$ \\
\hline Potassium $(\mathrm{K}) *$ & $473.14^{\mathrm{A}} \pm 3.06$ & $441.98^{\mathrm{B}} \pm 5.72$ & $413.12^{C_{ \pm}} 1.92$ & $410.42^{C_{ \pm}} 0.56$ \\
\hline Sodium $(\mathrm{Na}) *$ & $221.12^{\mathrm{A}} \pm 1.12$ & $215.85^{\mathrm{B}} \pm 0.72$ & $206.13^{C} \pm 0.18$ & $200.05^{\mathrm{D}_{ \pm}} \pm 0.56$ \\
\hline Calcium $(\mathrm{Ca}) *$ & $208.89^{D_{ \pm}} 0.30$ & $210.41^{C_{ \pm}} 0.52$ & $215.83^{\mathrm{B}} \pm 0.64$ & $227.06^{\mathrm{A}} \pm 0.05$ \\
\hline Magnesium $(\mathrm{Mg}) *$ & $99.05^{C_{ \pm}} 0.01$ & $100.06^{\mathrm{C}_{ \pm}} \pm .05$ & $129.81^{\mathrm{B}} \pm 1.21$ & $189.22^{\mathrm{A}} \pm 0.33$ \\
\hline $\operatorname{Iron}(\mathrm{Fe}) *$ & $9.04^{\mathrm{D}_{ \pm}} 0.01$ & $11.40^{\mathrm{C}_{ \pm}} 0.01$ & $17.00^{\mathrm{B}} \pm 0.01$ & $18.11^{\mathrm{A}} \pm 0.06$ \\
\hline
\end{tabular}

*The values are mean \pm standard deviation of the replicates.

The values with common superscript letters in each row are not significantly different $(\mathrm{p}<0.05)$.

\section{DISCUSSION}

\section{A. Proximate Compositions of Unfermented Avocado Seed flour and fermented Avocado Seed Flour Samples}

Moisture is the main factor that affects microbial growth and is considered as a critical factor for the shelf life of food. According to [9] the moisture content of powdered dry Avocado seeds is $15.10 \pm 0.14 \mathrm{~g} / 100 \mathrm{~g}$. According to the results there was no significant effect $(p<0.05)$ on the moisture content of unfermented Avocado seed flour when compared with fermented Avocado seed flour for all the incubation periods. Hence, the fermentation process does not affect the moisture content of Avocado seed flour.

Minerals in our diet are very important to maintain healthy bones, muscles, heart, and brain functions. According to this study, there was no significant effect $(p<0.05)$ on the ash content of avocado seed flour upon the fermentation with $L$. plantarum. Results obtained for the ash content for both fermented and dry unfermented seed flour agree with the results published in [10]. With an increase in the incubation period, there was a slight reduction in the total ash content in each of the samples. According to study of [11], the fermentation process that is carried out by microorganisms cause the extraction of soluble minerals into processing water, or usage of those minerals for the metabolic activities by microorganisms.

According to [12], P. americana is a good source of dietary protein and its high-fat content could contribute calories to man and animal ration. According to the study of [13], the protein content of seed flours increased with the fermentation. According to the results, it revealed that fermentation of avocado seed flour with $L$. plantarum shows a significant effect $(p<0.05)$ on the percentage crude protein content of seed flour. The results of this study highlight the gradual 
increase in the crude protein content of fermented Avocado seed flour with the incubation period, in which there was a $44 \%$ increment at $72 \mathrm{~h}$ incubation period.

This increase in crude protein content was mainly due to the capability of microorganisms to degrade cellulolytic materials during the fermentation upon secretion of extracellular enzymes. Further, it may cause be caused by the increased production of single-cell proteins by microorganisms due to an increase in microbial nitrogen during their fermentation process [14].

Crude fibre is a quantity of indigestible cellulose, pentoses, lignin, and other components present in food that provides health benefits. According to the study in [9], the results show that the crude fibre content of the avocado pear seed flour was about $2.87 \%$. This study shows a higher fibre content, and it could serve as a good dietary fibre source providing more health benefits. Crude fibre plays an important role to improve the bulkiness of food, the satisfaction of appetite, gastrointestinal motility, and improving the absorption and reabsorption of cholesterol and bile acids respectively, and thereby could lower cholesterol levels and prevent the formation of plaque [9]. According to the results of this study, there was no significant $(\mathrm{p}<0.05)$ difference between the dry unfermented Avocado seed sample and the sample fermented for $24 \mathrm{~h}$. However, there was a significant difference between the unfermented sample and those fermented for $48 \mathrm{~h}$ and as well as $72 \mathrm{~h}$. It confirms that when carry out fermentation process for $48 \mathrm{~h}$ to $72 \mathrm{~h}$, it may cause to significant decrease of crude fibre content of Avacado seed flour. According to the study of [11], it may cause due to fibrous tissues in seeds become soft during the microbial fermentation process and conversion of dietary fibre and lignocelluloses that present in seeds into proteins by microorganisms.

According to the results of this study, it is revealed that fermentation using $L$. plantarum does not significantly change $(\mathrm{p}<0.05)$ the crude fat content. These results confirm the fact that fermentation using L. plantarum does not induce a significant effect $(p<0.05)$ on the crude fat content of avocado seed flour. According to the results of this study, it indicates that both fermented and dry unfermented avocado seed flour has a higher fat content than reported in [11]. Fermentation increases crude fat content upon forming simple fatty acids due to the breakdown of large fat molecules.

The carbohydrate content of Avocado seed flour, according to [10] is $47.35 \pm 3.24 \%$ and in contrast, value stated in [9] showed $80.12 \pm 0.15 \%$. The results obtained for this study show an intermediate value when compared with both fermented and dry unfermented Avocado seed flour samples. According to the results, total carbohydrate content has reduced during fermentation. According to the study in [11], it may be due to the formation of simple sugars upon the bioconversion of complex sugars during fermentation or use as an energy source for microbial growth and metabolism.

\section{B. Analysis of the Quantity of Most Important Minerals of Unfermented and Fermented Avocado Seed Flour}

In this study, Potassium (K), Sodium (Na), Magnesium $(\mathrm{Mg})$, Calcium $(\mathrm{Ca})$, and Iron $(\mathrm{Fe})$ contents were determined in each of dry unfermented and fermented avocado seed flour sample. According to the results, $\mathrm{Na}$ and $\mathrm{K}$ contents were significantly decreased $(\mathrm{p}<0.05)$ with the fermentation periods. Na content was shown as $221.12^{\mathrm{A}} \pm 1.12,215.85^{\mathrm{B}}{ }_{ \pm}$ $0.72,206.13^{C_{ \pm}}+0.18,200.05^{D} 0.56$ for $0 \mathrm{~h}, 24 \mathrm{~h}, 48 \mathrm{~h}$, and $72 \mathrm{~h}$ respectively. $\mathrm{K}$ contents of each sample was shown as 473.14 ${ }^{A} \pm 3.06,441.98^{B_{ \pm}}+5.72,413.12^{C} \pm 1.92,410.42^{C}+0.56$ for $0 \mathrm{~h}, 24 \mathrm{~h}, 48 \mathrm{~h}$, and $72 \mathrm{~h}$, respectively

$\mathrm{Ca}, \mathrm{Mg}$ and $\mathrm{Fe}$ contents were significantly increased $(\mathrm{p}<0.05)$ with the incubation periods. For $0 \mathrm{~h}, 24 \mathrm{~h}, 48 \mathrm{~h}$ and $72 \mathrm{~h}$ of fermented Avocado seed flour, Ca content was shown $208.89^{\mathrm{D}_{ \pm}}+0.3,210.41^{\mathrm{C}_{ \pm}}+0.52,215.83^{\mathrm{B}} \pm 0.64,227.06^{\mathrm{A}} \pm 0.05$ and $\mathrm{Mg}$ content was shown $99.048^{\mathrm{C}_{ \pm}} 0.01,100.06 \mathrm{C}_{ \pm 0.050 \text {, }}$ $129.81^{\mathrm{B}} \pm 1.21,189.22^{\mathrm{A}} \pm 0.33$ respectively. Fe content was shown $9.043^{\mathrm{D}_{ \pm}} 0.01,11.40^{\mathrm{C}} \pm 0.01,17.00^{\mathrm{B}} \pm 0.01,18.11^{\mathrm{A}} \pm$ 0.06 for $0 \mathrm{~h}, 24 \mathrm{~h}, 48 \mathrm{~h}$ and $72 \mathrm{~h}$ fermented Avocado seed flour samples respectively. According to the study of [15], it may cause due to the reduction of oxalate and phytate content of seeds with the fermentation which are complexed with minerals to affect the bioavailability of those minerals.

\section{CONCLUSION}

The percentage of moisture, crude protein, crude fat, crude fibre, and total carbohydrate content of dry unfermented Avocado seed flour is $13.63 \pm 0.40 \%, \quad 6.42 \pm 0.08 \%$, $9.30 \pm 0.08 \%, 4.90 \pm 0.13 \%$ and $62.92 \pm 0.61 \%$ respectively and for fermented Avocado flour(72h) are $15.57 \pm 0.30 \%$, $9.26 \pm 0.28 \%, 8.97 \pm 0.06 \%, 4.05 \pm 0.16 \%$ and $59.57 \pm 0.81 \%$ respectively. Fermentation of Avocado seed flour using $L$. plantarum had significantly increased $(\mathrm{p}<0.05)$ on crude protein content, crude fibre content and total carbohydrate content at the maximum incubation period of $72 \mathrm{hrs}$.

The contents of $\mathrm{K}, \mathrm{Na}, \mathrm{Ca}, \mathrm{Mg}$ and $\mathrm{Fe}$ for dry unfermented avocado seed flour are $473.14 \pm 3.06 \mu \mathrm{g} / \mathrm{g}, 221.12 \pm 1.12 \mu \mathrm{g} / \mathrm{g}$, $208.89 \pm 0.299 \mu \mathrm{g} / \mathrm{g}, 99.05 \pm 0.006 \mu \mathrm{g} / \mathrm{g}$ and $9.04 \pm 0.012 \mu \mathrm{g} / \mathrm{g}$, respectively and in fermented Avocado seed flour $(72 \mathrm{~h})$, are $410.42 \pm 0.056 \mu \mathrm{g} / \mathrm{g}, 200.050 \pm 0.56 \mu \mathrm{g} / \mathrm{g}, 227.06 \pm 0.050 \mu \mathrm{g} / \mathrm{g}$, $189.22 \pm 0.327 \mu \mathrm{g} / \mathrm{g}$, and $18.11 \pm 0.06 \mu \mathrm{g} / \mathrm{g}$, respectively. The contents of $\mathrm{Fe}, \mathrm{Mg}$ and $\mathrm{Ca}$ had significantly $(\mathrm{p}<0.05)$ increased with the incubation period $(72 \mathrm{~h})$ and $\mathrm{K}$ and $\mathrm{Na}$ contents were significantly $(\mathrm{p}<0.05)$ reduced with fermentation period of Avocado seed flour. Fermentation of Avocado seed flour for $72 \mathrm{hrs}$ enhance the nutritional quality.

\section{REFERENCES}

[1] Filannino P, Tlais A, Morozova K, Cavoski L, Scampiccho M, Gobbetti $M$ et al. Lactic acid fermentation enriches the profile of biogenic fatty acid derivatives of avocado fruit (Persea americana Mill.). Food Chemistry.2020;317:1-9.

[2] Dabas D, Shegog R, Ziegler G, Lambert J. Avocado (Persea americana) Seed as a Source of Bioactive Phytochemicals. Current Pharmaceutical Design. 2013;19(34):6133-6140.

[3] Adaramola B, Onigbinde A, Shokunbi O. Physiochemical properties, and antioxidant potential of Persea Americana seed oil. Chemistry International. 2016;2(3):168-175.

[4] Mechmeche M, Kachouri F, Ksontini H, Hamdi M. Production of bioactive peptides from tomato seed isolate by Lactobacillus plantarum fermentation and enhancement of antioxidant activity. Food Biotechnology. 2017;31(2):94-113.

[5] Abdelazez A, Heba A, Zhu Z, Sami R. Potential benefits of Lactobacillus plantarum as probiotic and its advantages in human health and industrial applications: A review. Advances in Environmental Biology. 2018;12(1).

[6] Jayusy, Setiawan D, Giyarto. Physical and Chemical Characteristics of Jackfruit (Artocarpus Heterophyllus Lamk.) Seeds Flour Produced 
Under Fermentation Process by Lactobacillus Plantarum. Agriculture and Agricultural Science Procedia. 2016; 9:342-347.

[7] AOAC International, \& Latimer G.W. (2012). Official method of analysis of AOAC International. Gaisthersburg, Md: AOAC International.

[8] Pequerul A, Pérez C, Madero P, Val J, Monge E. A rapid wet digestion method for plant analysis. Optimization of Plant Nutrition. 1993;3-6.

[9] C Egbuonu A. Proximate, Functional, Antinutrient and Antimicrobial Properties of Avocado Pear (Persea americana) Seeds. Journal of Nutritional Health \& Food Engineering. 2018;8(1).

[10] Nwaogu L, Alisi C, Ojiako O. Studies on the Nutritional and Phytochemical Properties of Persea americana Seed. Bioresearch. 2009;6(1):320-322.

[11] Igbabul B, Hiikyaa O, Amove J. Effect of Fermentation on the Proximate Composition and Functional Properties of Mahogany Bean (Afzelia africana) Flour. Current Research in Nutrition and Food Science Journal. 2014;2(1):01-07.

[12] Talabi J, Osukoya O, Ajayi O, Adegoke G. Nutritional and antinutritional compositions of processed Avocado (Persea americana Mill) seeds. Pelagia Research Library Asian Journal of Plant Science and Research. 2016;6(2):6-12.

[13] Simwaka J, Chamba M, Huiming Z, Masamba K, Luo Y. Effect of fermentation on physicochemical and antinutritional factors of complementary foods from millet, sorghum, pumpkin, and amaranth seed flours. International Food Research Journal. 2017;24(5):18691879.

[14] Munishamanna K, Suresha K, Veena R, Subramanya S. Solid State Fermentation of Mango Peel and Mango Seed Waste by Different Yeasts and Bacteria for Nutritional Improvement. International Journal of Food and Fermentation Technology. 2017;7(1):111.

[15] Nkhata S, Ayua E, Kamau E, Shingiro J. Fermentation, and germination improve nutritional value of cereals and legumes through activation of endogenous enzymes. Food Science \& Nutrition. 2018;6(8):2446-2458. 